\title{
Moda y comida: una alianza que predice hechos económicos
}

\section{Veneziani, Marcia [ver currículum del autor, docente de la Facultad de Diseño y Comunicación]}

\section{Resumen:}

Las tendencias extremas entre el lujo y la simplicidad se ponen en evidencia desde los lugares más sorprendentes. La indumentaria y la alimentación expresan ese legendario y a la vez nuevo arte, como un modo de expresión, sofisticación y diferenciación cada vez más excesivo. Se fusionan dos necesidades básicas para erigirlas en el pedestal de lo artístico, integrando la participación del consumidor. ¿De dónde surgen estos cruces? ¿Por qué y cuándo se producen? Algunos países se valen de la sinergia entre los vínculos de sus tradiciones culinarias y de moda para lanzar el made in y así expresar sus identidades nacionales. El vínculo entre el ropaje y la alimentación (aparentemente extravagante) se ligan desde hace unos años para poner en evidencia no sólo la crisis económica global y local, sino también el manifiesto de que también el lujo hoy pasa por la sencillez de lo básico.

Palabras clave:

lujo - simplicidad - comida - moda - arte - crisis económica - identidad.

Algunas disquisiciones acerca de sus causas

Tanto la moda como el alimento han mantenido un vínculo desde un aspecto más psicológico y social lo suficientemente conflictivo como para determinar los estereotipos de belleza de las distintas épocas. Tácitos testimonios son las pinturas de diversos momentos, periódicos y novelas del siglo XIX y XX (por no ir más atrás en el tiempo). Este nexo implica otras cuestiones que contienen hábitos y costumbres tradicionales. Pero no se 
trata aquí de efectuar un análisis histórico, sino más bien de encontrar las razones por las que ese enlace entre dos tópicos, aparentemente tan discordantes, se manifiesta actualmente en el diseño.

Extrañas y por momentos extravagantes, las tendencias cada vez más extremas entre el lujo y la simplicidad se ponen en evidencia en la actualidad desde los lugares más sorprendentes. La moda y la comida expresan ese legendario y al mismo tiempo nuevo vínculo, como un modo de expresión, sofisticación y diferenciación. ¿De dónde surgen estos cruces? ¿Por qué se producen? Lo hemos mencionado en publicaciones anteriores: las modas expresan aquello que se manifiesta en la sociedad. Es por ello que se considera más que oportuno ahondar en una primera instancia en algunas cuestiones sociológicas y económicas que ayudarán a explicar este particular maridaje entre la indumentaria y la comida. En estudios previos (Veneziani, 2007), se ha analizado el pensamiento de George Simmel (1924), quien sostiene que el ser humano se debate en un constante movimiento de opuestos. Es decir, brega entre adaptarse y moldearse en el propio grupo social y en el de destacarse y emerger el propio "yo" individual. Esta fuerza que lleva a cohesionarse con el propio grupo, por un lado brinda la tranquilidad de la aquiescencia por parte del entorno y, por el otro, permite pronunciarse abiertamente sobre sí mismo. Eximiría -como afirma el sociólogo alemán- de la propia responsabilidad. De allí que la moda como imitación de un modelo existente ofrece la seguridad de la aprobación social. La imitación, además de dar seguridad de pertenencia a un grupo, ratifica el hecho de alcanzar a quien se remeda. Es decir, permite satisfacer la exigencia de distinción, ya que las modas de la clase superior difieren de las inferiores. El mismo autor se refiere también al hecho de instituir un circuito limitado y al mismo tiempo, separarlo de los otros. Además, apenas las clases inferiores comienzan a imitar a las superiores, las segundas, para conservar las diferencias con los otros estratos sociales, tratan de impedir la imitación introduciendo nuevos estilos, modas o códigos. Parecería además verificarse una vinculación económica que se relaciona con la razón sociológica expresada por Simmel en 1924. El primer economista que hizo referencia al tema fue el norteamericano Thorstein Veblen quien en 1899 desarrolló su famosa: Teoría de la clase ociosa (1944) realizando un cabal análisis respecto del vestido como expresión de la cultura pecuniaria. Según el mencionado autor, a través del ropaje se ostenta la propia situación económica y ello se realiza con el fin de acreditar y conseguir una apariencia en función de los otros. A tal punto que esa vestimenta, además de su elevado costo, tiene que hacer evidente que la persona en cuestión no ejerce ninguna labor lucrativa, es decir, que sólo se dedica a consumir determinados productos y lucir los atuendos de última moda, como así también a mantener un estilo de vida dispendioso. Por su parte, José Ortega y Gasset en su reconocido libro la Rebelión de las masas (1929), asevera que el hombre necesita siempre una razón de ponderación en la sociedad. El dinero, no ya como acopio de capital sino como parámetro de elegancia, vendría a consumar esa relación resultando así la moda el testimonio representativo de su poder. En sus reflexiones el autor considera épocas del imperio crematístico a aquellas sometidas al poder del dinero, sosteniendo que se corresponden con períodos de transición entre dos etapas. Es decir, al entrar en crisis una determinada contextura política y moral, la sociedad no inviste fundamentos de categorías sociales, lo que el mismo pensador considera como un impulso primario de la socialización. No importa cuál sea éste, pero siempre se dará un principio de rangos en una comunidad. Recordando sus palabras y reflexionando nuevamente acerca de la ostentación se nos presentan de gran actualidad nuevamente sus palabras: “...durante un momento -el siglo XVI- en Holanda, el hombre más envidiado era el que poseía cierto raro tulipán. La fantasía humana, hostigada siempre por ese instinto irreprimible de jerarquía, inventa siempre algún tema de desigualdad" ([1927 ]1984, p. 254) Para el filósofo español, estas cuestiones se cristalizan de un modo más evidente en períodos de crisis. Pues bien, ¿qué sería para Ortega y Gasset un período de tales características? Podría ser considerado como un tiempo en el cual no 
sólo "la moral ni la religión dominan la vida social ni el corazón de la muchedumbre" sino también considera que la cultura intelectual y artística es valorada menos que en las dos décadas anteriores ([1927]1984, p. 254) Si se presta atención a las fechas de las observaciones de los autores citados, se advertirá que fueron períodos previos a grandes crisis económicas. De allí podemos inferir que, antes o casi al mismo tiempo de períodos de tales características, la necesidad de ostentar se vuelve cada vez más importante. Esto aparentemente paradójico ya se lo pudo observar en estudios previos -en la Belle Époque previa a la Primera Guerra Mundial, en los años veinte antes de la profunda crisis del 29 y en años previos a la fuerte crisis del 2008- (Veneziani, 2012). Vayamos ahora a profundizar en la crisis económica más reciente, con el fin de sustentar con más evidencia la hipótesis anteriormente desarrollada. La misma inició el año anterior debido a la denominada "burbuja inmobiliaria" que comenzó en los Estados Unidos de Norteamérica y que repercutió en el sistema financiero general de ese país para extenderse luego a otras naciones del mundo. Esto provocó, entre otras cuestiones, la caída de la bolsa de 2008 y una crisis alimentaria posterior a nivel internacional. Este brete económico repercutió particularmente en España en el mismo año, manifestándose en la denominada "crisis inmobiliaria o hipotecaria" que redundó en diversas problemáticas sociales (desempleo, descreimiento institucional y político), en la acentuación de conflictos ya existentes relacionadas con cuestiones identitarias, también vinculadas al propio territorio (profundización de movimientos de independencia regional, entre otros).

\section{El surgimiento en España y el fortalecimiento de la Marca País}

Esta expresión de máxima sofisticación denominada Cook \& Fashion nace a mediados de la década que va desde el 2000 al 2010 en España. Su sede emplazada en San Sebastián, organiza eventos internacionales en el que se proponen desfiles de prendas de reconocidos diseñadores locales mientras el público prueba comidas también diseñadas por famosos chefs que "combinan" (desde su textura, color, aroma y sabor) con los primeros, o viceversa. Los diseñadores "crean" platos que luego sirven de inspiración para diseñar vestidos. En su misma página web definen este exclusivo concepto (acompañado por un elegante diseño de Victorio \& Lucchino) como: "Clásico, creativo, internacional y lujoso" (Cook \& Fashion, 2015). Pareciera que, previamente a una crisis profunda (como se hizo mención más arriba), si se la graficase en una curva decreciente, ésta comenzaría con una importante elevación inicial y con una caída abrupta posterior (como preanunciando un derrumbe económico). España, ha aprovechado la sinergia entre dos de sus fortalezas: la antigua tradición culinaria y la del diseño de indumentaria -que desde hace unos cuántos años viene evidenciando una internacionalización cada vez más manifiesta de sus diseñadores locales- para continuar fortaleciendo la "Marca España" y así paliar las dificultades económicas. Entre las numerosas marcas y diseñadores internacionales que participan se encuentran: Cristóbal Balenciaga, Escada, Marina Rinaldi, Max Mara, Leire Santillán, Jesús Del Pozo, Francis Montesinos, Agatha Ruiz De La Prada, David García, Antonio Alvarado, José Miró, Raia Oiartzabal, Ali de Bali, Aurelia Gil, Amaia Txabarria, Callejeras \& Abel Tanguas. Estos eventos, además de contar con el auspicio del Gobierno De España y de la Comunidad Económica Europea, se han realizado en el mismísimo Parlamento Europeo de Bruselas, en el Balenciaga Museum, en el Chillida Museum y en varios lujosos hoteles de San Sebastián y Madrid. La propuesta se ha extendido a través de los años a otros países: en el 2015 se efectuaron en París, New York, México, y para el 2016 se proyectan unos cuántos más, y muy exclusivos en Tokio, Las Vegas, Perú y Münich. España ha sabido aprovechar esta iniciativa con el fin de promover estas dos fuerzas vitales para comunicar posteriormente su "Marca País": la alimentación y la vestimenta, que son dos necesidades básicas del ser humano: el abrigo y la alimentación. Este binomio pareciera estar recordándolas. 
En el año 2013 nace la Asociación Española del Lujo para potenciar la etiqueta Made in Spain de alta gama y así contribuir a la implementación de una estrategia para el relanzamiento de la economía en crisis de ese país.

El Estado español ocupa el quinto lugar en el "mercado del lujo" dentro de la Unión Europea. El sector de productos y servicios de lujo "Made in Spain" cerró 2012 con una facturación de unos 4.788 millones de euros, el 15\% más que en 2011. Un fuerte repunte que contrasta con el descenso generalizado del consumo y que se apoya en el impulso que genera la venta de estos productos a los turistas extranjeros. (Dorronsoro, L., 2014)

España aprovecha ese mix de tradición e innovación para fomentar la exportación a través del mercado del lujo a variados mercados como el ruso, chino y alemán.

Italia: relanzando el "Made in"

En el año 2007, Fulvio Bonavia, un fotógrafo conceptual italiano, publica el libro A matter of taste. En éste, el artista vincula la moda y la comida poniendo en evidencia la cuestión del "buen gusto". No es extraño entonces que, en momentos de crisis, se recurra a dos conceptos fundamentales para la supervivencia del ser humano: la alimentación y el abrigo. Si bien el artista hace un guiño y juega con estos dos conceptos, los vincula con el lujo. No es casual que haya surgido en ese momento. ¿Quién puede tener acceso a la vestimenta y accesorios más caros? ¿Y a los mejores alimentos? (sobre todo a los más representativos de la cultura italiana) Bonavia mezcla ingredientes y fotografía de accesorios efímeros: desde carteras realizadas con exquisitos arándanos, frambuesas, moras o queso parmigiano reggiano, un cinturón de tallarines con engarces de plata, paraguas de semillas, zapatos de berenjenas, sombreros de alcauciles con aplicaciones de brillantes o anillos de jamón y plata. En el 2011 el fotógrafo italiano realiza una producción para Garage Magazine jugando con marcas de lujo como Louis Vuitton, McQueen, Moncler y Prada combinando prendas con alimentos básicos como cáscaras de nueces, hojas de coliflor, anchoas y cítricos. (Battaglia, G., 2011) Para el 2015, el concepto se instala y se inaugura en el imponente Foro Imperiale de Roma, específicamente en I mercati di Traiano, una exposición que reúne la moda y la comida bajo la mirada de diseñadores locales y extranjeros, consagrados y emergentes: indumentos, accesorios, fotografías, videos y entrevistas para hablar de este dúo tan particular. Los fuertes de la cultura italiana, la cocina y la moda, son recreados para volver a lanzar el Made in Italy, empleando la sinergia de este binomio enmarcado en un escenario que evoca los tiempos del Imperio Romano para relanzar una economía en crisis. Con "Agua, Aire, Tierra y Fuego", las tendencias globales fueron representadas en una muestra única que tuvo entre tantos expositores a Armani, Etro, Gattoni, Agatha Ruiz de la Prada o las maravillosas fotografías de la artista coreana Yeonju Sung. (L’eleganza del cibo, 2015)

Más casos de una tendencia que refleja la crisis económica y se expresa en la moda

A partir del año 2008, cuando estalló de lleno la crisis económica, el mercado del calzado deportivo lanzó una serie de diseños vinculados con la comida. Nike con Lobsters (2008) unas zapatillas inspiradas en un plato de langostas o Newcastle Pale Ale que remiten a un vaso de cerveza; Picnics (2010) imitando un sugestivo mantel campestre a cuadros rojos y blancos; la japonesa Asics (2009) y Vans en el 2011 hacen lo propio con Cheeseburgers and Fries. Franc Fernández crea el famoso y provocador vestido de carne para Lady Gaga (2010) que luce con zapatos, cartera con engarces de brillantes y sombrero del mismo material. A su vez, la inglesa Karen Karmody responde a la provocación con creaciones empleando vegetales. Otro es el caso de Anna Marconi, quien en el año 2011 crea un blog que reúne los dos conceptos al que denomina Taste of 
Runway. Allí se pueden observar fotos de creaciones de Mary Katrantzou, Hermès, Dolce\&Gabbana, entre tantos otros, inspirados en recetas de comida dulce y salada que refleja sus dos pasiones. Una inspira a la otra y crea originales parejas que reflejan un caleidoscopio multicolor. En el año 2014 a medida que se enfatiza la crisis económica europea, pasarelas y escaparates se "visten de alimentos" de modo acelerado. Moschino, con el concepto cheap and chic, muestra una modelo que posa sobre cajas de frutas y verduras, y en su pasarelas desfilan creaciones inspiradas en marcas de comidas rápidas y snacks, chocolates y golosinas, accesorios y vestidos de novia con recetas nutricionales. Vidrieras de Dolce \& Gabbana lucen cajones de frutas con calzados, carteras y frutas secas: un combo que se mezcla para evidenciar el maridaje. Karl Lagerfeld deslumbró con una pasarela en la semana de moda de París para presentar la colección invierno 2014/2015. El Grand Palais fue escenario de un desfile ambientado en un supermercado con productos de las góndolas (agua mineral, aceite de oliva, té, café, detergentes, latas de sardinas, productos de ferretería, limpieza, etc) y animado por modelos que empujaban carritos de supermercado vestidas con indumentos y calzados cómodos reflejando la simplicidad y elegancia del espíritu de Coco. (CHANEL Fall-Winter 2014/15 Ready-to-Wear show) La tendencia crece y el mismo año, en New York, The International Culinary Center lanza una campaña publicitaria que se viraliza rápidamente en las redes sociales para promocionar sus cursos de cocina empleando una hidden camera. Una modelo sube a un subterráneo y comienza a comer su cartera de chocolate, sorprendiendo a los transeúntes que, un poco desconcertados y entre sonrisas y asombro, no pueden creer lo que ven. (Taylor, 2014) Por su parte, Aló, una agencia de Comunicación y Relaciones Públicas que opera en la Argentina, realizó para Lycra, uno de sus más reconocidos clientes, la campaña Lycra Food \& Fashion con el fin de personalizar las cuatro tendencias de moda globales Otoño - Invierno 2015 y Primavera -Verano 2015-2016 en un libro de moda y gastronomía. Como sostienen sus directoras Soledad Depresbítero y Florencia Cajide: "Se abordó el desafío de unir tres disciplinas distintas: el diseño de modas, la gastronomía y la fotografía". (comunicación personal, 4 de julio de 2015) La diseñadora Eva Nowodworski, de la marca Las Pepas, partió de la consigna de hacer cuatro conjuntos para invierno y otros tantos para el verano. Por su parte, Pablo Massey, reconocido chef de este país, se inspiró en sus figurines e ideas, brillos y texturas para elaborar platos que pudiesen "combinar" con cada uno de ellos. Para completar el engarce, el fotógrafo de modas y publicidad Gustavo Saiegh registró el material para el libro de Recetas dándole un encuadre personal que pudiese registrar aquello que se deseaba transmitir desde la marca. Se organizó un evento para 200 personas y se convocó a proveedores, comunicadores y estudiantes de diseño. Los asistentes fueron invitados a degustar los platos, tocar y ver los diseños en un desfile. "Desde todos los sentidos" fue la original consigna de la propuesta. Para Eva Nowodworski, la inspiración nace en diversos lugares y no es fácil determinar en dónde. Explica que para encontrar las estampas de las ocho tendencias se fue fijando en cual era la "esencia". Prendas holgadas y adherentes, que marcan un recorrido sobre el cuerpo, son parte de la propuesta. "Vestirse con la naturaleza" fue también una de las consignas que la inspiró para crear desde la tendencia Existencial que se proponía a nivel global. Con cada conjunto la diseñadora explica que se logró producir un acting que representara la misma. Por su parte, Masey buscó situaciones que se vincularan con los colores y texturas de los diseños de Eva. El resultado: una combinación interdisciplinaria que reúne "todos los sentidos" para mostrar creativamente las tendencias globales: confluencia, disonancia, existencia y sustancia.

No se trata sólo de moda

Quien haya dedicado unos años a estudiar los actos de consumo y comunicación sabe reconocer que aquellos aunque disfrazados de una aparente espontaneidad e inocencia- están dotados de una buena carga de 
irracionalidad y contenido emocional.

Dogana (1984), quien realizó profundos análisis psicológicos de las conductas del ser humano frente a los bienes de consumo, sostiene:

Observando los modos de conducta respecto de la adquisición y del consumo en nuestra sociedad se recoge la clara impresión de que los bienes, de cualquier tipo y de cualquier nivel, tienen primariamente la función de distinguir y personalizar a sus adquirientes. El proceso de adquirir, aun las cosas más triviales, se hace así sumamente trabajoso y complicado: el objeto que hay que elegir, aun el más insignificante, debe exhibir en efecto siempre algo típico, único, diferente, algo que indique la originalidad y la individualidad de su poseedor. Apelar a la "personalización" es uno de los medios más difundidos en las promesas publicitarias. Lo anónimo, lo común, lo compartido con otros llega a ser sinónimo de falto de valor. (p. 243)

Por ello, la tarea de analizar las conductas humanas vinculadas al consumo de moda no puede simplificarse, ni tampoco escindirse de otras muchas variables que necesariamente se deben abordar desde otras disciplinas para convertirse en un entramado más vasto de los hechos sociales. ¿Cómo afecta esta mirada a la enseñanza y la práctica del diseño? Como se hizo referencia en estudios anteriores, el hecho que las diferentes expresiones artísticas sean el reflejo de su contexto social y económico no es una sorpresa, y viene a fundamentar una vez más, la tesis de que la visibilidad de la moda permite el fino análisis capaz de predecir hechos económicos futuros. (Veneziani, 2012) El vínculo entre el ropaje y la alimentación (aparentemente extravagante) se liga desde hace unos años para poner en evidencia no sólo la crisis económica global y local, sino que además permite descubrir las claves interpretativas del mundo de la apariencia y la elegancia bajo el manto de aquello aparentemente escueto. Citando una frase atribuida a Coco Chanel: "La simplicidad es la clave de la verdadera elegancia". Se evidencia en la actualidad, que el lujo se nutre de la sencillez de lo primordial. ¿Y qué hay más básico que el alimento y el abrigo? Para concluir y seguir debatiendo sobre el tema: ¿acaso las fotografías que se suben a las redes sociales mostrando las comidas en lugares de moda no estarían indicando algo más significativo que el aparente e ingenuo acto de comer?

\section{Bibliografía}

Battaglia, G. (2011) Recuperado de: http://garagemag.com/fashion-eatmewearme/ Bonavia, F. (2008) A matter of taste, Sydney: Hachette. CHANEL Fall-Winter 2014/15 Ready-to-Wear show - Full Film. Disponible en: https://www. youtube.com/watch?v=YLDUXZ4X5b8 Cook \& Fashion (2015). Recuperado de: http://www.cookandfashion.com/ Dogana, F. (1984). Psicopatología del consumo cotidiano. Barcelona: Gedisa.

Dorronsoro, L. (2014). Recuperado de: http://www.abc.es/economia/20140105/abciapuesta-lujo-made-spain201401032009.html L'eleganza del cibo (2015). Tales about food and fashion. Recuperado de: http://www. mercatiditraiano.it/mostre_ed_eventi/mostre/l_eleganza_del_cibo Marconi, A. (2015). Recuperado de: http://www.tasteofrunway.com/about/ Ortega y Gasset, J. La rebelión de las masas [1927](1984). Barcelona: Planeta. Simmel, G. (1924). Filosofía de la coquetería, filosofía de la moda, lo masculino y lo femenino y otros ensayos. Madrid: Revista de Occidente. Taylor, V. (2014) Recuperado de: http://www.nydailynews.com/lifestyle/eats/model-eatschanel-purse-subway-article-1.1603738 / Veblen, T . [1899] 1944. Teoría de la clase ociosa. México: Fondo de Cultura Económica. Veneziani, M. (2007). La imagen de la moda. Buenos Aires: Nobuko. Veneziani, M. (2012). Moda, economía y sociedad. Buenos Aires: Nobuko. 
Abstract:

The extreme tendencies between luxury and simplicity become evident from the most surprising places. Clothing and food express that both traditional and contemporary art as a mode of expression, sophistication, and increasingly excessive differentiation. Two basic needs to establish them merge into the foundation of the artistic, integrating consumer participation. Where do these crossings arise? Why and when do they occur? Some countries use the synergy between the links of their culinary traditions and fashion to launch the "made in" and thus express their national identities. The link between clothing and food (apparently high) have been linked for several years to bring out not only the global and local economic crises, but also to show how luxury passes for the simplicity of the basics.

Key words:

luxury - simplicity - food - fashion - art - economic crisis - identity.

\section{Resumo:}

As tendências extremas entre o luxo e a simplicidade evidenciam-se nos lugares mais surpreendentes. A indumentária e a alimentação expressam esse legendário, e às vezes nova arte, como um modo de expressão, sofisticação e diferenciação cada vez mais excessivos. Se fundem duas necessidades básicas para relacionálas com o artístico, e integrando a participação do consumidor. De onde surgem esses cruzamentos? Por que e quando ocorrem? Alguns paises valem-se da sinergia entre os vínculos de suas tradicionais culinárias e de moda para lançar o made in e assim expressar suas identidades nacionais. O vínculo entre o vestuário e a alimentação ( em aparência extravagante) se ligam desde há alguns anos para destacar a crise econômica global e local, assim como o manifesto de que também o luxo hoje passa pela simplicidade do básico.

Palavras chave:

luxo - simplicidade - comida - moda - arte - crise econômica - identidade

Moda y comida: una alianza que predice hechos económicos fue publicado de la página 17 a página24 en Cuadernos del Centro de Estudios de Diseño y Comunicación № 64 